\title{
Acclimatization, Water Intake Adequacy Rate, Individual Characteristics and Heat Strain: A Cross-Sectional Study on Heat Exposed Workers
}

\author{
Kemala Imas Tejo Sutono, ${ }^{1, *}$, Yuliani Setyaningsih ${ }^{2}$, and Suroto ${ }^{2}$ \\ ${ }^{1}$ Undergraduate Student of Occupational Safety and Health, Faculty of Public Health, Diponegoro University, Semarang - Indonesia \\ ${ }^{2}$ Department of Occupational Safety and Health, Faculty of Public Health, Diponegoro University, Semarang - Indonesia
}

\begin{abstract}
Someone will have a greater risk of experiencing heat strains if working at a workplace exposed to heat. In addition to the heat from the body's metabolic results and the result of heat exposure from the work environment, heat strain on workers also influenced by individual factors. The extent to which an individual's body can tolerate heat exposure is determined by the condition of his body. Physiological changes will occur in the body of workers who exposed to heat. The objective of this study was to analyse factors related to heat strain such as acclimatization, water intake adequacy rate, and individual characteristics. The research was an observational analytic study and study design that used was cross-sectional. The population chosen as the research subject was workers who were exposed to heat. Purposively 57 construction workers were selected as subjects. To prove the relationship between acclimatization, water intake adequacy rate, and individual characteristics with heat strain, it used chi square statistical test. Physiological Strain Index (PSI) used to assess heat strain event on workers. The results of outdoor WBGT measurements at the study site showed that the average of WBGT outdoor was $31.11^{\circ} \mathrm{C}$. Heat strain with high index experienced by the majority of workers as much as $82.5 \%$. Result of statistical analysis showed the significance of each variable was acclimatization $(p<0.05)$, water intake adequacy rate $(\mathrm{p}<0.05)$, alcohol and drug consumption $(\mathrm{p}>0.05)$, health status $(\mathrm{p}>0.05)$, body mass index $(p<0.05)$, age $(p>0.05)$, and work period $(p>0.05)$. This study showed that there was a significant relationship between heat strain with acclimatization, water intake adequacy rate and body mass index. The relationship is evidenced by the results of bivariate analysis. However, there was no association between consumption of alcohol or drugs, health status, work period, and age with heat strain.
\end{abstract}

Keywords: acclimatization ; water intake adequacy rate ; physiological strain index ; heat strain ; heat stress

\section{Introduction}

Generally the discomfort that occurs in warm weather depends on the significant degree of temperature and humidity present in the air. The linkage between mortality and temperature have been examined by some researchers. ${ }^{[1-3]}$ In addition to this, the emergence of occupational health risks and the decline in productive workability are caused by climate change due to increased heat exposure. ${ }^{[4]}$

However, besides work environment conditions, and physical workload, the body condition of each worker also plays a role against the occurrence of heat strain because health problems on workers will not occur if there is a favourable balance of physical workload, the additional burden of the work environment, and work capacity. The work capacity is influenced by the condition of each individual. ${ }^{[5]} \mathrm{A}$ worker tolerance to heat pressure is determined by his body condition. ${ }^{[6]}$
Both occupational and personal may play different roles in various age groups. ${ }^{[7,8]}$ They are known as contributors to social inequalities in accidents, health and mortality. ${ }^{[7,9-11]}$

One example of worker who works with heat exposure is a construction worker. Exposure to solar radiation is quite a lot on this type of work because they always work outdoor. Indonesia is one of the countries receiving maximum sunlight and evenly throughout the year due to its location on the equator line. Each year the air temperature in Indonesia is $27^{\circ} \mathrm{C} .{ }^{12}$

Solar radiation is effected by localized events, which include cloudiness and visibility. If wind and radiation are to be considered as heat index variables, they are most suitable for a location as they can vary significantly in values over a short distance. ${ }^{[13]}$ Observational data of Meteorology, Climatology and Geophysics Agency (BMKG) since 1981-2016 showed that temperature trend in Indonesia has increased $0.03^{\circ} \mathrm{C}$ every year. ${ }^{[14]}$

\footnotetext{
Corresponding author: mailto:kemalaimasts@gmail.com
} 
The results of ISBB measurements at the study sites showed that from 8 points of measurement, all exceed the threshold value based on Regulation of Indonesian Minister of Labour number 5, 2018. The objective of this study is to analyse the relationship between individual factors, water intake adequacy rate, and acclimatization with the occurrence of heat strain.

\section{Method}

The research was an observational analytic study and study design that used was cross-sectional. 100 construction workers in iron fabrication, formwork, daily worker of Health Safety Environment (HSE), and housekeeping were the population of this research. The respondents taken are as many as 57 workers as research sample with proportionate random sampling technique. The research location is Package IV Airport Development Project. The research variables include independent variable and dependent variable. The independent variables were acclimatization, water intake adequacy rate, age, work period, body mass index, health status, alcohol and drug consumption. The dependent variable was heat strain. Data analysis used chi square statistic test.

\section{Results and Discussions}

The results showed that most respondents were young with the age of $<40$ years old $(73.7 \%)$. There were no significant differences between the distribution of respondents with long and short work period, worker with long work period were $47,4 \%$ and short work period were $52.6 \%$. Body mass index was dominated by normal category as much as $70.2 \%$. The majority of respondents were in good health as much as $87.7 \%$. Water intake adequacy rate varied considerably but in most of the worker $(35.1 \%)$ were in excessive categories. $71.9 \%$ of respondents have been acclimatized.

Table 1. Frequency Distribution of Independent and Dependent Variables of Heat Exposed Workers

\begin{tabular}{|l|r|r|}
\hline \multicolumn{1}{|c|}{ Variables } & \multicolumn{1}{c|}{ n } & \multicolumn{1}{c|}{ \% } \\
\hline Age & & \\
\hline Old & 15 & 26.3 \\
\hline Young & 42 & 73.7 \\
\hline Work Period & 27 & 47.4 \\
\hline Long & 30 & 52.6 \\
\hline Short & & \\
\hline Body mass index & 5 & 8.8 \\
\hline Obesity & 7 & 12.3 \\
\hline Overweight & 40 & 70.2 \\
\hline Normal & 5 & 8.8 \\
\hline Thin & & \\
\hline Health Status & 7 & 12.3 \\
\hline Not healthy & 50 & 87.7 \\
\hline Healthy & & \\
\hline $\begin{array}{l}\text { Alcohol or Drug } \\
\text { Consumption }\end{array}$ & 14 & 24.6 \\
\hline Yes & & \\
\hline
\end{tabular}

\begin{tabular}{|l|r|r|}
\hline \multicolumn{1}{|c|}{ Variables } & \multicolumn{1}{c|}{ n } & \multicolumn{1}{c|}{ \% } \\
\hline No & 43 & 75.4 \\
\hline Water Intake Adequacy Rate & & \\
\hline Severe Deficit & 13 & 22.8 \\
\hline Medium Deficit & 5 & 8.8 \\
\hline Low Deficit & 7 & 12.3 \\
\hline Normal & 12 & 21.1 \\
\hline Excessive & 20 & 35.1 \\
\hline Acclimatization & & \\
\hline No Acclimatization & 16 & 28.1 \\
\hline Acclimatization & 41 & 71.9 \\
\hline Heat Strain & & \\
\hline Very High & 5 & 8.8 \\
\hline High & 47 & 82.5 \\
\hline Moderate & 5 & 8.8 \\
\hline Low & 0 & 0.0 \\
\hline No & 0 & 0.0 \\
\hline
\end{tabular}

Based on the measurement of pulse rate and core body temperature, all respondents had heat strain but with a different index, the majority have a high index of $82.5 \%$. The normality test data showed that the data is abnormally distributed $(\mathrm{p}<0.05)$ so that the correlation test used was chi square test. The chi square test results are shown in Table 2.

Table 1. Frequency Distribution of Independent and Dependent Variables of Heat Exposed Workers

\begin{tabular}{|l|r|}
\hline \multicolumn{1}{|c|}{ Independent Variables } & p-value \\
\hline Age & 0.094 \\
\hline Work Period & 0.876 \\
\hline Body mass index & 0.041 \\
\hline Health Status & 0.428 \\
\hline Alcohol / Drugs Consumption & 0.381 \\
\hline Water Intake Adequacy Rate & 0.003 \\
\hline Acclimatization & 0.025 \\
\hline
\end{tabular}

\subsection{Correlation between Age and Heat Strain}

Based on the bivariate analysis, the proportion of young age that experienced heat strain with high index was 35 respondents $(83.3 \%)$ more than the older workers that were 12 respondents $(80.0 \%)$. The result of statistical analysis resulted p-value 0,094 showed that there is no significant correlation between age and heat strain.

Another study by Indra in 2014 on workers in the Hospital Kitchen showed that there was no correlation between age and subjective complaints due to heat stress. ${ }^{[15]}$ Based on the theory, the older a person the sweat gland response is slower and the process of sweating decreases its effectiveness making it difficult to release heat to the environment. In addition, getting older also causes increased blood flow to the skin when exposed to heat due to thermoregulation disorders associated with decreased efficiency of the sympathetic nervous system. ${ }^{[6]}$ Cardiac function becomes less efficient when a person has the age of 40-65 years leads to slower sweat exposure so it takes longer to restore the body to normal temperature. ${ }^{[16]}$ Chronic hypo hydration 
increases with age. Hypo hydration is a factor in high incidence of fatal and non fatal heat stroke in the old age group. In general, as the age increase, the higher likelihood of heart failure will be. In Europe and North America, only a few patients with heart failure are 50 years of age or younger, ${ }^{[17-19]}$ while those who are 65 years or older are the majority of heart failure patients, which is $80 \% .^{[20]}$ Countries with the majority of the elderly population will be predicted to have an increased number of patients with heart failure. ${ }^{[21]}$

Hypo hydration in old age causes a decrease in thirst response resulting in a reduction in plasma volume that can interfere with thermoregulation. ${ }^{[6]}$ In this study age was unrelated due to many factors other than age that affect the effectiveness of sweat and heart function such as health status, acclimation status, body mass index, and consumption of alcohol or drugs.

\subsection{Correlation between work period and heat Strain}

Based on the bivariate analysis, the proportion of short working period experienced heat strain with high index is 24 respondents $(80.0 \%)$ more than those who have long working period that is 23 respondents $(85.2 \%)$. The result of statistical analysis using chi square test results p-value 0,876 indicates that there is no significant correlation between age and heat strain.

There were researches on the domestic household industry fumigation, one in Kelurahan Ketapang, Kendal District and another one on the labor of PT Aneka Boga Makmur with the result of the studies that there is no correlation between work period with subjective complaint and heat strain event. ${ }^{[22,23]}$

The period of work is closely related to the accumulation of hazard exposure. The longer the work the greater is the exposure to the work environment, whether physical, chemical, biological, and others. In addition, people who have worked for a long period of time tend to regard crumbs as likely to be exposed to the negative effects of exposure in the work environment because they consider them to be commonplace, it potentially increasing the likelihood of occupational accidents or disease. ${ }^{[15]}$ Based on the theory, the longer a person works in the hot environment the more crystallization of urine is formed because the exposure to heat is getting more and more and prolonged. ${ }^{[24]}$ The occurrence of urine crystallization leads to poor health status so that it has a greater risk when they get exposed to the heat.

\subsection{Correlation between body mass index and heat Strain}

Based on bivariate analysis, the proportion of normal BMI who experienced heat strain with a high index of 35 respondents $(8.5 \%)$ and 2 obesity respondents experienced heat strain with very high index. The result of statistical analysis using chi square test result of $p$-value 0,041 indicates that there is significant correlation between BMI with heat strain.
The results of this study are in line with subjective complaint research due to the heat stress on workers at PT IGLAS (Persero) in 2013, body size has a significant relationship with the emergence of subjective complaints due to heat stress with strong moderate positive relationship which the greater the body size the more complaints will be felt by the respondents. ${ }^{[5]}$ According to theory, a person who is obese is at risk about 3,5 times more likely to suffer from heat related disorder. Broad body surface ratio causes the speed of heat loss to decrease. Obesity is also correlated with decreased physical fitness, maximum work capacity, and cardiovascular capacity. Comparison of body surface area with weight in obese people causes a decrease in heat loss process. The thicker the subcutaneous fat layer, the greater the barrier is between the skin to the underlying tissue, thereby reducing heat transfer directly from muscle to skin. ${ }^{[6]}$

\subsection{Correlation between health status and heat Strain}

Based on the bivariate analysis, the proportion of respondents with healthy status experienced heat strain with high index as many as 40 respondents $(80.0 \%)$. The statistical analysis using chi square test $\mathrm{p}$-value produce 0,428 indicates that there is no significant relationship between age and heat strain.

The results of this study are in line with the two previous studies, the first research is on the production of lubricants of PT Pertamina in 2012 with the result that there is no relationship between health status and the subjective complaint rate of heat pressure. ${ }^{[25]}$ Based on the theory, someone who suffered degenerative diseases such as cardiovascular system, diabetes, lungs, liver, or kidney have greater risk when exposed to the heat. ${ }^{[6]}$ When a person experiences degenerative cardiovascular disease then the risk of heat related illness will increases with impaired thermoregulation response. Hypothyroidism affects metabolism and body temperature directly. Patients with anaemia have a smaller number of red blood cells that affects the metabolism, cardiovascular system, and thermoregulation. ${ }^{[26]}$ A person in good health can also maintain core body temperature in the range of 36$37^{\circ} \mathrm{C} .{ }^{27}$ In this study, health status is not correlated to the heat strain occurrence statistically because the data obtained is less varied, i.e. $87.7 \%$ in good health, this happened because there has been an appeal from HSE for workers to not work when feeling unwell.

\subsection{Correlation between alcohol or drug consumption and heat Strain}

Based on bivariate analysis the proportion of respondents who consumed alcohol or drug with high heat strain index as many as 34 respondents $(79.1 \%)$ more than those who consume alcohol or drug that are 13 respondents $(92.9 \%)$. The result of statistical analysis using chi square test result p-value 0.381 showed that there is no significant correlation between alcohol or 
drug consumption and heat strain. The results of this study are in line with research on cracker factory workers in East Ciputat Sub district in 2014 which concluded that there is no relationship between the consumption of drugs with heat strain. ${ }^{[28]}$

According to theory, the consumption of alcohol or drugs can reduce the body's ability to work in a hot environment. ${ }^{[27]}$ Drugs that interfere with the thermoregulation process include antidepressants that can affect heart rate and reduce the level of sweat expenditure. Anti-hypertensive drugs can also reduce blood flow to the skin and reduce the cooling process in the body. In addition, diuretic drugs will also affect the balance of fluids in the body. Workers who get treatment should work in the supervision of the company's health department. Alcohol consumption can reduce heat tolerance and increase the risk of heat related illness. ${ }^{[6]}$

In this study the consumption of alcohol or drugs is not correlated to the occurrence of heat strain statistically because the employee's tolerance of alcohol has been highly seen that the history of workers has long been a habit of alcohol consumption so there are no significantly physiological changes in the body of workers after consuming alcohol. In addition, the collection of information about the consumption of drugs in this study is only done through interviews so that could become potentially bias information.

\subsection{Correlation between water intake adequacy rate and heat Strain}

Based on the bivariate analysis, the proportion of respondents who have moderate deficit of their water intake adequacy rate is 3 respondents $(60.0 \%)$, while those with excessive water intake had moderate heat strain index of 3 respondents $(15.0 \%)$. The result of statistical analysis using chi square test result $\mathrm{p}$-value 0.003 indicates that there is significant correlation between ages with heat strain.

The results of this study are in line with subjective complaint research due to heat stress in blacksmith workers in Desa Bantaran Probolinggo in 2016 which concludes that there is a significant relationship between the quantity of drinking water and the frequency of drinking water with subjective complaints due to heat stress. The relationship value between the two variables is negative so that the less drinking water is consumed, and the less frequency of drinking is done then the higher risk for subjective complaints occurs due to higher heat pressure. ${ }^{[29]}$

The theory says that the dehydration experienced by a person will increase the core body temperature faster. Body needs fluid replacement to overcome dehydration due to excessive sweating. Losing $\mathrm{NaCl}$ out with sweat can cause muscle pain (heat cramps) due to the body's inability to replace the loss of $\mathrm{NaCl}^{[27]}$

\subsection{Correlation between acclimatization and heat Strain}

Based on bivariate analysis, the proportion of acclimatized respondents suffering from heat strain with a very high index of as many as 4 respondents $(25.0 \%)$ is more than those who have not acclimatized as one respondent $(2.4 \%)$. The result of statistical analysis using chi square test resulted p-value of 0.025 indicates that there is significant correlation between age with heat strain.

The results of this study are in line with the research on workers in the household fish industry in Ketapang District Kendal with the result that there is a relationship between acclimatization with subjective complaints of heat stress. ${ }^{[22]}$ The theory says that in the body of a person who has been acclimatized will modify the mechanism of his sweat release so that the release of heat is more effectively. The acclimatized conditions of body heat exposure can reach $100 \%$ while the heart rate of body temperature can be lower. ${ }^{[27]}$

\section{Conclusion}

All respondents experiencing heat strain were dominated by heat strain with high index. Respondents were predominantly young, with short work period, normal BMI, healthy status, no alcohol or drug consumption, excessive water intake adequacy rate, and had been acclimatized. Factors correlated to heat strain occurrences in this study were BMI, water intake adequacy rate and acclimatization.

Thea decrease of hazard exposure in work environment will have positive impact on the quality of work environment. One of hazard in work environment is the work climate that influenced by several things such as carbon emissions in the air. High carbon emissions cause extreme climate changes that can trigger heat strains for heat exposed workers. Good quality of work environment will increase worker productivity and company profit.

\section{References}

1. Indonesian Ministry of Public Works and Housing. Sektor Konstruksi Tempati Posisi Ketiga Penyokong Pertumbuhan Ekonomi Indonesia 2016 [Internet]. 2017 [accessed on March 1st 2018]. Available on Indonesian Ministry of Public Works Website.

2. Indonesian Statistics Center. Quarterly Indonesian Gross Domestic Product 2013-2017. Jakarta: Indonesian Statistic Center. (2017).

3. Stallworth, J., Kleiner, B. Recent developments in office design. Journal of Facilities. (1996), 14 (1/2), pp. 34-42.

4. Norianggono YCP, Hamid D, Ruhana I. Effect of Physical and Non-Physical Work Environment on Employee Performance (Study on Employee of PT Telkomsel Area III Jawa-Bali Nusra in Surabaya). Jurnal Administrasi Bisnis (JAB). 2014;8(2). 
5. Leshabari M, Muhondwa E, Mwangu M, Mbembati $\mathrm{N}$ : Motivation of Health care workers in Tanzania: case study of Muhimbili National Hospital 2008, East African journal of Public Health,:5(1):30-36.

6. World Meteorological Organization. The Global Climate 2011-2015: Heat Recors and High Impact Weather [Internet]. 2016 [accessed on March 4th 2018]. Available on WMO website.

7. Occupational Safety and Health Administrator. US Department of Labor's OSHA Announces June 4 Safety Stand-down at Rok Sites Throughout Southeast to Focus on Heat-related Illnesses and Injuries [Internet]. 2013 [accessed on March 4th 2018]. Available on OSHA website.

8. National Safety Council. Summer Heat Can be Deadly for Construction workers, CPWR Cautions [Internet]. [accessed on March 4th 2018]. Available on Safety and Health Magazine Website.

9. Gogh, K.T. Sudden unexplained death syndrome among Thai workers in Singapore. Paper presented at the National Epidemiology Seminar, Bangkok, Thailand. (1990).

10. Yoopat, P., Glinsukon, T., Vanwonterghem, K., Louhevaara, V., \& Vanoeteren. The First International Workshop on Health and Working Conditions in South East Asia (Commission of the European Union. J. Heat stress and physical workload. In Proceedings. (1999).

11. $\mathrm{Yi} \mathrm{W,} \mathrm{Chan} \mathrm{APC.} \mathrm{Effects} \mathrm{of} \mathrm{heat} \mathrm{stress} \mathrm{on}$ construction labor productivity in Hong Kong: A case study of rebar workers. International Journal of Environmental Research and Public Health. 2017;14(9).

12. Harrianto R. Occupational Health Textbook. Hardiyanti EA, editor. Jakarta: EGC (2010).

13. Jacklitsch B, Williams W, Musolin K, Coca A, Kim J-H, Turner N. NIOSH Criteria for A Recommended Standard: Occupational Exposure to Heat and Hot Environments. US Department of Health and Human Services. (2016).
14. Fadhilah R. Factors Related to Heat Strains on Crackers' Factory Workers in East Ciputat District in 2014. Syarif Hidayatullah Islamic State University; 2014.

15. Istiqomah FH, Nawawinentu ED. Dominant Factors that Influence the Emergence of Subjective Complaints of Heat Stress on Workers at PT. IGLAS (Persero) Year 2013. The Indonesian Journal of Occupational Safety and Health. 2013;2(2):175-84.

16. Golbabaei F, Monazzam MR, Aval MY, Taban E, Rostami M, Shendi A. Investigation of Heat Stress and Heat Strain in Outdoor Workers : A Case Study in Iran. Journal of Paramedical Sciences. 2016;7(4):30-8.

17. Bates GP, Schneider J. Hydration status and physiological workload of UAE construction workers: A prospective longitudinal observational study. Journal of Occupational Medicine and Toxicology. 2008;10:1-10.

18. Adiningsih R. Factors Affecting Heat Strain Events in Heat Exposed Workers at PT Aneka Boga Makmur. The Indonesian of Occupational Safety and Health Airlangga University. 2013;2:145-53.

19. Puspita AH. Analysis of Heat Stress and Subjective Complaint Level on Workers in the Jakarta Lubricant Production Area of PT Pertamina (Persero) in 2012. University of Indonesia. (2012).

20. Soeripto M. Industrial Hygiene. Jakarta: Balai Penerbit FKUI. (2008)

21. Yoopat P, Toicharoen P, Glinsukon T. Ergonomics in Practice: Physical Workload and Heat Stress in Thailand. International Journal Of Occupational Safety and Ergonomics (JOSE). 2002;8(1):83-93. 